\title{
Effect of Silicon and Calcium on Human Dental Pulp Cell Cultures
}

\author{
Jomana Alsenan, Laisheng Chou* \\ Email address: \\ jomana@bu.edu (J. Alsenan), Lchou@bu.edu (Laisheng Chou) \\ ${ }^{*}$ Corresponding author
}

Department of Restorative Sciences \& Biomaterials, Goldman School of Dental Medicine, Boston University, Boston, USA

\section{To cite this article:}

Jomana Alsenan, Laisheng Chou. Effect of Silicon and Calcium on Human Dental Pulp Cell Cultures. International Journal of Materials Science and Applications. Vol. 6, No. 6, 2017, pp. 290-296. doi: 10.11648/j.ijmsa.20170606.14

Received: September 10, 2017; Accepted: September 21, 2017; Published: December 4, 2017

\begin{abstract}
This study was designed to investigate the odontogenic effects of Silicon, Calcium and Phosphorous on human dental pulp cells. Human dental pulp cells derived from extracted pristine teeth were cultured in growth media with supplements of Si 25ppm, Si 25ppm+Ca 8.3ppm, Si 25ppm+Ca 8.3ppm+P 4.16ppm, Si 50ppm, Si 50ppm+Ca 16.7ppm, Si $50 \mathrm{ppm}+\mathrm{Ca} 16.7 \mathrm{ppm}+\mathrm{P} 8.3 \mathrm{ppm}$ and media without additional supplement as control, for the time intervals of 16 hours, 7, 12 , and 21 days. Cell proliferation rates were measured by the optical density of crystal violet dye stained cells. ALP activity was measured by fluorometric assay. Expression of Dentin Sialoprotein (DSP) was measured by ELISA. Mineralization of cultures was measured by Alizarin Red staining. The data were presented as the mean of triplicates and normalized on a per million cell basis. Statistical analysis was conducted using ANOVA and Tukey HSD post-hoc tests. Culture with 50ppm supplemental Si at day 21 yield significantly higher levels of ALP activity, DSP expression and mineralization $(P<0.05)$ compared to the control group and other supplemented groups. Cultures with $\mathrm{Si} 25 \mathrm{ppm}+\mathrm{Ca} 8.3 \mathrm{ppm}$ supplemental and $\mathrm{Si} 50 \mathrm{ppm}+\mathrm{Ca} 16.7 \mathrm{ppm}$ supplemental displayed significantly higher cell proliferation rates compared to the control group at day $12(P<0.05)$ and at day $21(P<0.05)$. Supplemental silicon in concentration of $50 \mathrm{ppm}$ could significantly induce differentiation and mineralization of normal human dental pulp cells. Calcium has a synergetic effect in up-regulating the proliferation rates. This is the first report to demonstrate the silicon- and calcium-induced mineralized tissue formation of human dental pulp cell cultures, leading to the potential development and clinical application of a future novel dental pulp capping material.
\end{abstract}

Keywords: Pulp Capping, Odontogenesis, Silicon, Calcium

\section{Introduction}

Preservation of pulp vitality is of prime importance, especially in immature teeth where root formation has not yet been completed [1]. Pulp capping is one of the treatment options where the materials used ideally have sufficient physicochemical properties, stimulate the pulpal odontoblasts to form a dentinal bridge, and induce remineralization and healing [2-5]. Over the years, there has been controversy among researchers about the pulp-capping agent used, and not the procedure itself. Calcium hydroxide $(\mathrm{CH})$ and mineral trioxide aggregate (MTA), two of the present treatment options do not exclusively stimulate dentinogenesis; instead, they induce the formation of mineralized tissue because of their high $\mathrm{pH}$ levels $[6,7]$.
Investigations in vitro on osteoblastic cells demonstrated a significant correlation between the concentration of silicon (Si), cell proliferation and mineralization rate [8-10]. Yet, the mechanism behind Silicon's effect on cell behavior is not fully understood. Extracellular calcium (Ca) concentration can play a dose- dependent role in increasing bone cell proliferation [11]. Another study on bone cell proliferation found a strong correlation between $\mathrm{Ca}$ and phosphorous (P) ratios [12]. The study showed increased cell proliferation with higher $\mathrm{Ca} / \mathrm{P}$ ratio, and an inhibitory effect in response to a lower ratio. Bioglass ceramics and other silicate based glasses release ionic products in the physiological medium, among these $\mathrm{Si}, \mathrm{Ca}$ and $\mathrm{P}$. These ions play an essential role in bone tissue engineering as they are the main components of biological apatite $[13,14]$. To determine the stimulatory effect of these ions on human dental pulp cells (hDPCs) 
proliferation and differentiation, it is important to know their optimal concentrations/combinations to develop a new pulp capping material that will ultimately induce an odontogenic effect.

\section{Materials and Methods}

\subsection{Cell Isolation and Culture}

All human dental pulp explants used in this investigation were obtained from two pristine extracted $3^{\text {rd }}$ molars of an 18-years old female patient after obtaining informed consent at the oral surgery department of Boston University School of Dental Medicine. hDPCs were isolated using the published procedure described by Stanislawski et al. with modifications [15]. Briefly, teeth were scored sagitally with a high-speed hand piece and 330 bur using copious water spray without entering the pulp chamber. Then, by using a bi-bevel chisel, teeth were sectioned and dental pulp tissue was collected immediately with cotton pliers. The pulp tissue was cut into pieces and placed into $25 \mathrm{ml}$ flasks containing culture medium which was maintained in a humidified atmosphere at $37^{\circ} \mathrm{C}$ with $5 \% \mathrm{CO}_{2}$. The culture medium consisted of Eagle's Basal Medium (BME) (Gibco), with supplements of $10 \%$ fetal bovine serum (Atlanta Biologicals), $100 \mathrm{U} / \mathrm{mL}$ of penicillin $\mathrm{G}$ (Gibco), $100 \mathrm{mg} / \mathrm{mL}$ streptomycin (Gibco), and $2.5 \mathrm{mg} / \mathrm{mL}$ amphotericin-B (Gibco). Culture media were replaced every three days. Cells were grown to confluence, then trypsinized $(0.05 \%$ trypsin, Life Technologies $)$ and transferred into $250 \mathrm{ml}$ flasks containing media as described above. When cells again reached confluence, they were trypsinized and subsequently counted with a hemocytometer (Reichert-Jung) under a microscope following a method as described by Freshney [16]. Cells were suspended at $3 \times 10^{3}$ per $\mathrm{ml}$ and transferred to 24 -well plates and cultured. At this stage, cells were immediately seeded in culture media with different concentrations and combination groups.

\subsection{Material Preparation}

Pure silica gel with 5 to $25 \mu \mathrm{m}$ particle size (Aldrich Chemical Co.) was used to prepare the silicon supplement. Calcium chloride (Sigma) was used for the calcium supplement. Anhydrous sodium phosphate, dibasic, (Fisher Biotech) was utilized for the phosphorous supplement. Seven containers were prepared with $500 \mathrm{~mL}$ culture media (CM) each. Under sterile conditions, groups of materials were supplemented as follows:

Group 1: CM with 25 ppm Si ion supplementation.

Group 2: $\mathrm{CM}$ with $25 \mathrm{ppm} \mathrm{Si}$ and $8.3 \mathrm{ppm} \mathrm{Ca}$ ion supplementation.

Group 3: CM with 25 ppm Si, 8.3 ppm Ca and 4.16 ppm P ion supplementation.

Group 4: CM with 50 ppm Si ion supplementation.

Group 5: $\mathrm{CM}$ with $50 \mathrm{ppm} \mathrm{Si}$ and $16.7 \mathrm{ppm} \mathrm{Ca}$ ion supplementation.

Group 6: CM with 50 ppm Si, 16.7 ppm Ca and 8.3 ppm P ion supplementation.
Group 7: Control (CM without extra ion supplementation).

Silica gel was sterilized via autoclaving prior to its use. Medium containing any combination of $\mathrm{Ca}$ or $\mathrm{P}$ were sterilized by $0.2 \mu \mathrm{m}$ filtration.

Table 1. Media Supplemented with Various Concentrations and Combinations.

\begin{tabular}{llll}
\hline \multirow{2}{*}{ Group Name } & \multicolumn{3}{l}{ Supplemented element concentrations (ppm) } \\
\cline { 2 - 4 } & Si & Ca & P \\
\hline Group 1 & 25 & 0 & 0 \\
Group 2 & 25 & 8.3 & 0 \\
Group 3 & 25 & 8.3 & 4.16 \\
Group 4 & 50 & 0 & 0 \\
Group 5 & 50 & 16.7 & 0 \\
Group 6 & 50 & 16.7 & 8.3 \\
Group 7 (Control) & 0 & 0 & 0 \\
\hline
\end{tabular}

\subsection{Measurement of Cell Attachment and Proliferation}

Human dental pulp cells were seeded in a concentration of $3 \times 10^{3}$ in each well of the 24 well plates (Fisher Scientific) containing $1 \mathrm{~mL}$ culture media of different material groups as described above. Each condition was prepared in triplicate. The 24-well plates were incubated for 16 hours in saturated humidity of $37^{\circ} \mathrm{C}$ and $5 \% \mathrm{CO}_{2}$. At 16 hours, cell attachment was quantified through direct cell counts of floating cells using a hemocytometer (Reichert-Jung) and normalized to the initial cell seeding density.

Cell proliferation studies were determined at time points of 7, 12 and 21 days. At each predetermined time point, CM was removed and cells were fixed with $10 \%$ neutral buffered formalin (Sigma) for one hour at room temperature (RT). Fixer solution was then discarded and plates were washed twice with $1 \mathrm{X}$ PBS and stained with $1 \mathrm{ml} 0.2 \%$ crystal violet stain (Sigma Aldrich) [17] for 1hour at RT. Unbound stain was removed by rinsing plates thoroughly with deionized water until the rinse was clear. Optical density (O.D) value was then measured using a microplate reader (TECAN, Infinite 200 Pro) at a wavelength of $590 \mathrm{~nm}$. Absorbance of crystal violet is directly proportional to cell numbers.

\subsection{Screening of Odontoblast Phenotypic Markers}

For differentiation and mineralization studies, growth media were replaced with pre-odontogenic inductive medium for a total of 48-hours before each predetermined time interval: 12 and 21 days. Pre-odontogenic media consists of $10 \%$ charcoal stripped fetal bovine serum FBS (Gibco), 100 $\mathrm{U} / \mathrm{mL}$ Penicillin G (Gibco), $100 \mathrm{mg} / \mathrm{mL}$ Streptomycin (Gibco), $10^{-8} \mathrm{M}$ Menadione (Sigma Aldrich), $10 \mathrm{mM} \beta$ Glycerophosphate (Sigma Aldrich), $1.5 \mathrm{mg}$ L-ascorbic acid (Sigma Aldrich), and $2 \mathrm{mM} \mathrm{L-glutamine} \mathrm{(Fisher} \mathrm{Scientific)}$ in BME media (Gibco). Under sterile conditions, $\mathrm{Si}, \mathrm{Ca}$ and $\mathrm{P}$ were added to the pre-odontogenic inductive media as described above of different material groups. Cell culture plates at 11 and 20 days were cultured for an additional 24hours in fresh pre-odontogenic inductive medium to which was added $10 \mathrm{nM}$ VitD3 (Sigma). The supernatant fluid was collected at days 12 and 21. ALP activity and Dentin Sialoprotien (DSP) production were measured from the 
collected supernatants. The remaining fixed cells in culture plates were used to perform the mineralization assay. The odontogenesis phenotype was confirmed by VitD3.

\subsection{Measurement of Alkaline Phosphatase (ALP) Activity}

Alkaline phosphatase activity was measured using an ALP fluorometric assay kit (Abcam) according to the manufacturer's instructions. Supernatants at days 12 and 21 were utilized in this test. $100 \mu \mathrm{L}$ of culture supernatants were incubated with $20 \mu \mathrm{L}$ of the non-fluorescent 4methylumbelliferone phosphatase disodium salt (MUP) substrate in each well of a 96 well black plate with clear bottom (Thermo Scientific). The plates were subsequently incubated for 30 minutes at $25^{\circ} \mathrm{C}$ in the dark. During that time, MUP substrate was dephosphorylated to the fluorescent 4-methymbelliferone by active ALP obtained in the supernatants. The enzymatic reaction was then stopped with $20 \mu \mathrm{L}$ stop solution. Emission of the fluorescent substrate was measured at $440 \mathrm{~nm}$ using a microplate reader (TECAN, Infinite 200 Pro). The enzymatic activity was calculated by generating a standard curve and normalized to ALP activity on a per million cell basis.

\subsection{Measurement of Dentin Sialoprotein (DSP)}

Expression levels of secreted dentin sialoprotein were determined by the Dentin Sialoprotein (Bio Assay ${ }^{\mathrm{TM}}$ ) enzyme-linked immunosorbent assay kit (Human), (US Biologicals) in $100 \mu \mathrm{L}$ supernatants following the manufacturer's instructions. Supernatants at days 12 and 21 were utilized in this assay. Cell culture supernatants were centrifuged to remove debris. Triplicate samples and standards were initially mixed with $100 \mu \mathrm{L}$ of balance buffer and incubated with $50 \mu \mathrm{L}$ DSP-HRP conjugate for 1 hour at $37^{\circ} \mathrm{C}$. Then wells were washed five times and incubated with $100 \mu \mathrm{L}$ substrate for HRP enzyme for 15 minutes in the dark at room temperature. The reaction was stopped by adding 50 $\mu \mathrm{L}$ stop solution and absorbance was measured at $450 \mathrm{~nm}$ in a microplate reader (TECAN, Infinite 1000 Pro). A standard curve was plotted relating the intensity of the color (O.D.) to the concentrations of the standards. The DSP concentration in each sample was interpolated from this standard curve and normalized to the DSP expression levels on a per million cell basis.

\subsection{Measurement of Mineralization}

Mineralization was examined through accumulation of calcium deposition using Alizarin Red S staining [18]. The attached cells in the 24 -well plates at days 12 and 21 were employed for this test. First, the cells were rinsed twice with PBS and then fixed with $1 \mathrm{~mL} 10 \%$ formalin (Sigma) for 1 hour at room temperature. Formalin was aspirated and plates were rinsed twice with PBS before the cells were stained for 20 minutes with $1 \mathrm{~mL}$ of a $40 \mathrm{mmol} / \mathrm{L}$ Alizarin Red $\mathrm{S}$ (Sigma), pH 4.2 solution. Subsequently, unbound stain was removed by rinsing the plates thoroughly with deionized water until rinse water was clear. Later, absorbance was measured at a wavelength of $405 \mathrm{~nm}$ (TECAN, Infinite 200 Pro). Each condition was normalized to a per million cell basis.

\subsection{Statistical Analysis}

Statistical analysis was performed using JMP Pro 12 (ver. 12.1.0) in one-way variance statistical analysis with Tukey multiple comparison post hoc test. Differences were considered significant at $P<0.05$.

\section{Results}

\subsection{Attachment Efficiency Affected by Si, Ca, and P at Various Concentrations}

Cell attachment efficiency of hDPCs at 16 hours showed no significant increase in any of the supplemented groups compared to the control group.

\subsection{Proliferation Rate Affected by Si, Ca, and P at Various Concentrations}

No significant increase in the number of cells was found in the supplemented groups as compared to the control group at day 7 (Figure 1). At 12 and 21 days, a significant increase in cell number was only observed in groups number 2 ( $\mathrm{Si} 25$ ppm, Ca 8.3 ppm) and 5 (Si 50 ppm, Ca 16.7 ppm) $(P<0.05)$.

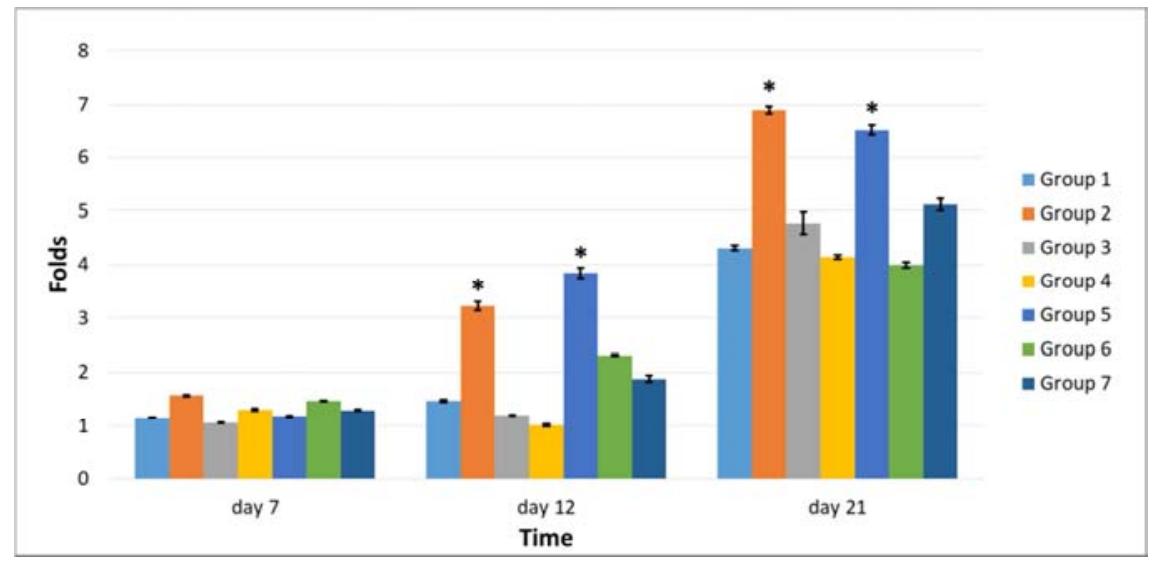

Figure 1. Proliferation of Human Dental Pulp Cells in Media Supplemented with Various Concentrations and Combinations of Si, Ca and P for a Time Period of 7,12 and 21 Days. $(* P \leq 0.05)$. 


\subsection{ALP Activity Affected by Si, Ca, and P at Various Concentrations}

At days 12 and 21, group number 4 ( $\mathrm{Si} 50 \mathrm{ppm}$ ) exhibited significantly higher ALP expression than the control group and all other groups $(P<0.05)$. Additionally, the control group demonstrated significantly higher ALP production than the remaining supplemented groups (Figure 2).

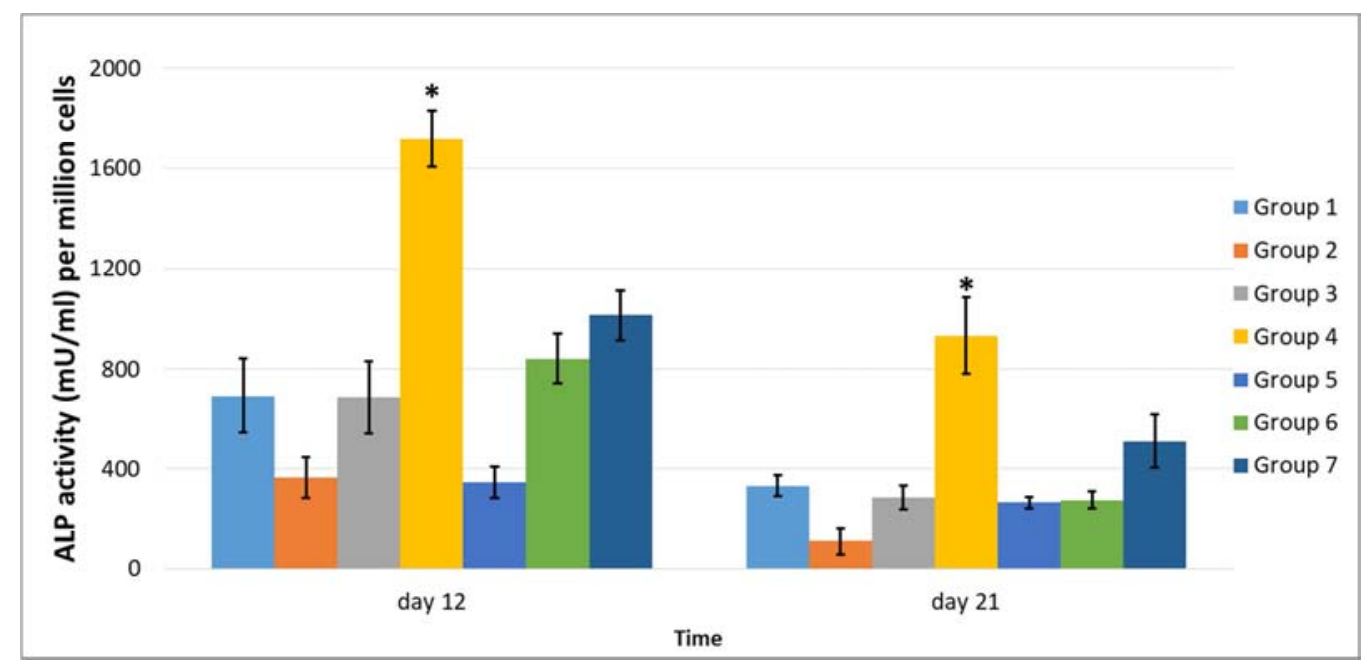

Figure 2. Alkaline Phosphatase Activity of Human Dental Pulp Cells in Media Supplemented with Various Concentrations and Combinations of Si, Ca and P for a Time Period of 12 and 21 Days. ( $\left.{ }^{*} P \leq 0.05\right)$.

\subsection{DSP Production Affected by Si, Ca, and P at Various Concentrations}

The highest values of secreted DSP on day 12 were derived from cells from supplemental groups number 1 ( $\mathrm{Si}$ 25 ppm), 3 (Si 25 ppm, Ca 8.3 ppm, P 4.16 ppm) and 4 (Si 50 ppm) $(P<0.05)$. At 21 days, the highest protein production was detected in group number 4 supplement only $(P<0.05)$. All groups other than group number 4 exhibited no significant differences between each other and or to the control group at day 21 (Figure 3).

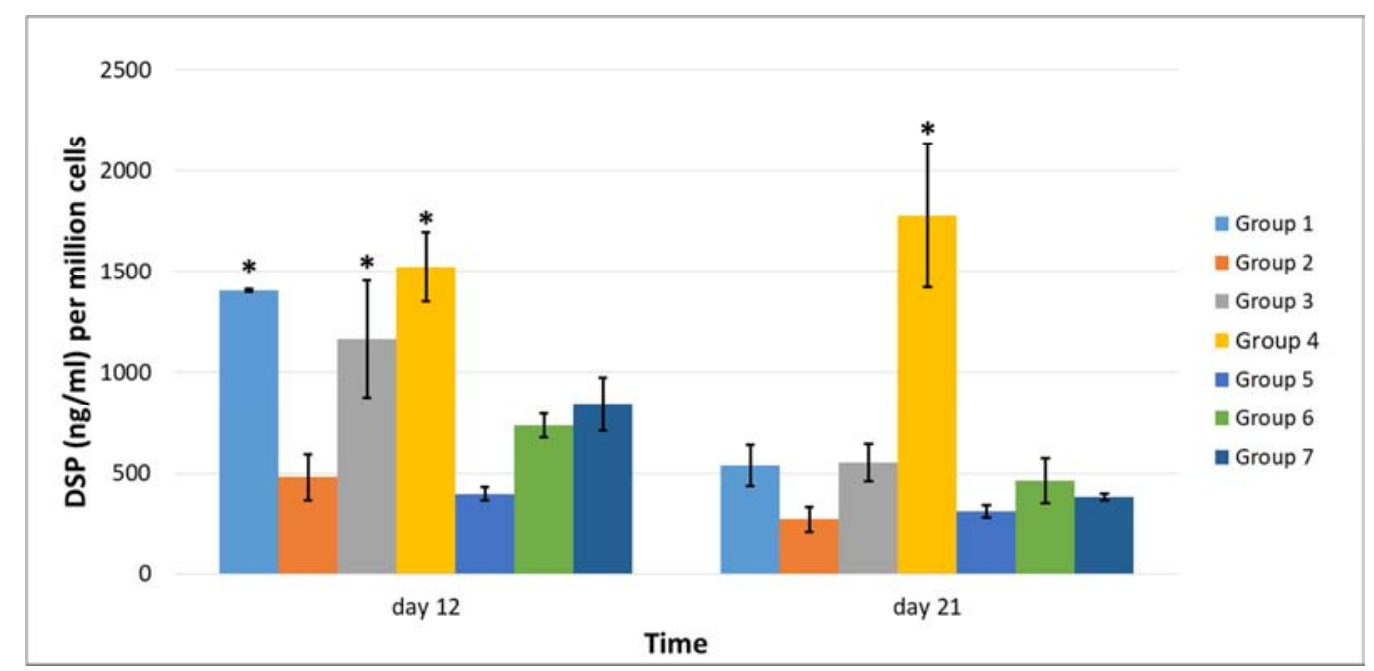

Figure 3. Dentin Sialoprotein Expression of Human Dental Pulp Cells in Media Supplemented with Various Concentrations and Combinations of Si, Ca and P for a Time Period of 12 and 21 Days. $(* P \leq 0.05)$.

\subsection{Mineralization Affected by $\mathrm{Si}, \mathrm{Ca}$, and $\mathrm{P}$ at various Concentrations}

Figure 4 shows data for bone nodule formation and calcium deposition from mineralization. At day 12, group number 4 (Si $50 \mathrm{ppm}$ ) demonstrated a significantly higher mineralization rate compared to the control group and all other groups $(P<0.05)$. However, groups number 1 (Si 25 ppm), 3 (Si 25 ppm, Ca 8.3 ppm, P 4.16 ppm) and 6 (Si 50 ppm, Ca 16.7 ppm, P 8.3 ppm) displayed higher values than the control group but still lower than group number 4 . At day 21 , group number 4 ( $\mathrm{Si} 50 \mathrm{ppm}$ ) clearly increased the area of calcified nodules up to 5.2-fold compared to the control group $(P<0.05)$. There were no significant differences between other groups at 21 days. 


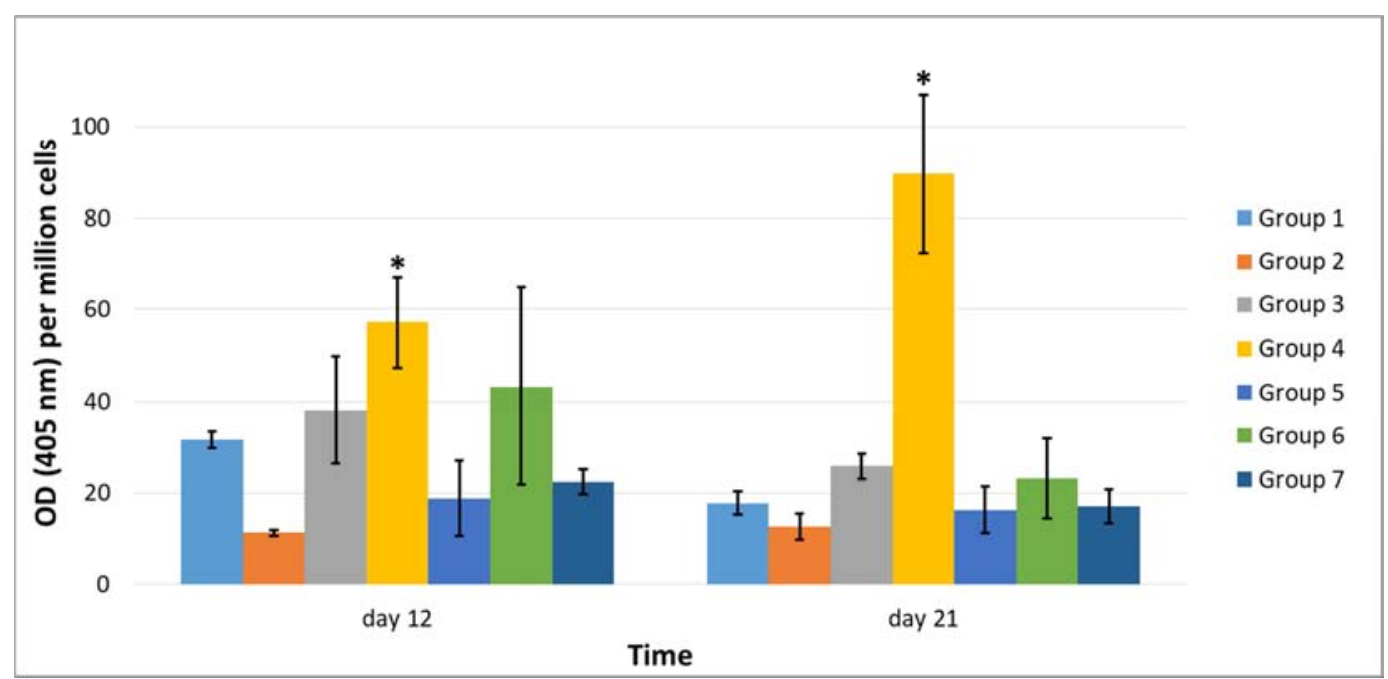

Figure 4. Mineralization of Human Dental Pulp Cells in Media Supplemented with Various Concentrations and Combinations of Si, Ca and P for a Time Period of 12 and 21 Days. $(* P \leq 0.05)$.

\section{Discussion}

Dental pulp is a highly-complex sensory organ, which allows progenitor cells to partially compensate for loss of enamel or dentine caused by dental caries, iatrogenic sources or trauma. The dental pulp progenitor cells give rise to a new generation of odontoblasts that stimulate the healing process by producing reparative dentin [19]. Calcium hydroxide was the gold standard pulp capping agent for several decades, due to its excellent antibacterial properties and its ability to form dentinal matrix [20-22]. Although it facilitates formation of mineralized tissue over the pulp wound area, it does not stimulate dentinogenesis per se [5, 23, 24]. Histologically, calcium hydroxide produces reparative dentine with tunneling defects which expose the pulp to bacterial penetration and infection over time [25-28]. In addition, due to its high $\mathrm{pH}$ level, a foci of necrosis develops at the site of exposure [29]. Mineral trioxide aggregate (MTA) was initially used as a root-end filling material. Later, it was used for pulp capping, apexogenesis, restoration of root perforations, and several other procedures. In many studies, MTA has shown superior biocompatibility, decent sealing ability $[3,30,31]$ and exhibits a higher success rate than calcium hydroxide [32, 33]. However, MTA exhibits major drawbacks in terms of handling difficulty, long setting time, tooth discoloration and high cost [34]. There are no studies so far that investigate the biocompatibility and mineralization of hDPCs in the presence of $\mathrm{Si}, \mathrm{Ca}$ and $\mathrm{P}$ ions.

In this study, individual ions and their mixtures were formulated to test their odontogenic potential effect on hDPCs. Alkaline phosphatase activity, dentin sialoprotein expression and mineralization were selected as specific markers of hDPCs differentiation.

Silicon studies on osteoblasts revealed enhanced proliferation rates and gene expression by influencing metabolism, bone formation and mineralization of human osteoblasts [35-37]. In other osteoblast studies, Si promoted proliferation as measured by DNA and alkaline phosphatase activity $[38,39]$. Also, calcium ions in the extracellular fluid of bone tissue demonstrated significant effect on proliferation and differentiation [40]. However, so far there are no reports that display the effect of $\mathrm{Si}, \mathrm{Ca}$ and $\mathrm{P}$ ions on hDPCs cultures. In this study, the groups containing $\mathrm{Si}$ and $\mathrm{Ca}$ demonstrated significant upregulation in cell proliferation rates when compared to the control group, indicating that combining $\mathrm{Si}$ and $\mathrm{Ca}$ can be beneficial for the growth of hDPCs. Additionally, groups supplemented with $\mathrm{Si}$ alone or in addition with $\mathrm{Ca}$ and $\mathrm{P}$ decreased the proliferation rates. There was a report showing an inhibitory effect of $\mathrm{P}$ on proliferation of rat bone marrow cells, where in that study, cells were cultured with various bioglasses and inhibition was related to high $\mathrm{P}$ ion release or high phosphate-rich precipitation [41].

Various studies demonstrated that the osteogenic activity in osteoblast cultures was improved upon by bioactive glass treatment [38, 39, 42-45]. The presence of increased levels of $\mathrm{Si}$ led to increased levels of ALP expression in human osteoblast cells [38]. The results of our study coincide with the osteogenic studies. In our study, it shows that expression of ALP was significantly highest at Si $50 \mathrm{ppm}$ concentration. Interestingly, the peak of ALP expression was reached at day 12 , and declined when it reached day 21. Detecting an inverse relationship between proliferation and differentiation supports the theory that if cells are more proliferative, the differentiation of the cells declines, and vice versa [46]. Usually, ALP is present in the early stage of differentiation [47]. Therefore, it is speculated in our study that the highest activity was reached at day 12 and declined afterward.

DSP is one of the markers of mature odontoblast cells and dentin production that is produced only by these cells and has not been found in other cells [48, 49]. Dentin sialophosphoprotein (DSPP) is cleaved into DSP by the terminally differentiated odontoblasts to prompt mineralization and dentinogenesis [50]. A previous study had 
observed higher levels of DSP expression in MTA-treated dental pulp tissue than in tissue treated with Biodentine. These findings illustrate the ability of MTA and Biodentine to induce new reparative dentin, but with MTA, production of dentin has better characteristics [50]. The results of our study show summiting of DSP levels in group supplemented with $\mathrm{Si}$ at $50 \mathrm{ppm}$. This finding is especially valuable because it clearly shows the stimulatory effect of Si on odontogenesis.

When odontoblasts differentiate, mineral deposition accumulates to form new dentine [51]. The mineralization study at day 21 became a pattern for the one recorded from DSP expression. This result is possibly caused by delayed mineralization, which could be explained by the prolonged proliferation and delayed differentiation $[52,53]$. Apparently, Si 50 ppm supplement has an up-regulating proliferative and odontogenic effect on hDPCs. Taken together, it can be concluded that Si 50 ppm supplemented concentration would produce the most proliferation, differentiation and mineralization up-regulation.

\section{Conclusion}

This study demonstrated that supplemented silicon at 50 ppm can significantly induce differentiation and mineralization of hDPCs. Silicon supplement combined with calcium has a synergistic effect in significantly up-regulating the proliferation rates in normal hDPCs. This is the first report to demonstrate that silicon and calcium induced mineralized tissue formation, pointing the way to the potential development and clinical application of a future novel dental pulp capping material.

\section{Acknowledgements}

The authors deny any conflicts of interest related to this study.

\section{References}

[1] Ricketts, D., Restorative dentistry: Management of the deep carious lesion and the vital pulp dentine complex. Br Dent J, 2001. 191(11): p. 606-610.

[2] Yu, F., et al., Effect of an Experimental Direct Pulp-capping Material on the Properties and Osteogenic Differentiation of Human Dental Pulp Stem Cells. Scientific Reports, 2016. 6: p. 34713.

[3] Cho, S.-Y., et al., Prognostic Factors for Clinical Outcomes According to Time after Direct Pulp Capping. Journal of Endodontics, 2013. 39(3): p. 327-331.

[4] Komabayashi, T., et al., Current status of direct pulp-capping materials for permanent teeth. Dental Materials Journal, 2016. 35(1): p. 1-12.

[5] Hilton, T. J., Keys to Clinical Success with Pulp Capping: A Review of the Literature. Operative dentistry, 2009. 34(5): p. 615-625.

[6] Nowicka, A., et al., Tomographic Evaluation of Reparative
Dentin Formation after Direct Pulp Capping with $\mathrm{Ca}(\mathrm{OH})_{2}$, MTA, Biodentine, and Dentin Bonding System in Human Teeth. Journal of Endodontics, 2015. 41(8): p. 1234-1240.

[7] Holland, R., et al., Reaction of rat connective tissue to implanted dentin tubes filled with mineral trioxide aggregate or calcium hydroxide. Journal of Endodontics, 1999. 25(3): p. 161-166.

[8] Christodoulou, I., et al., Dose- and time-dependent effect of bioactive gel-glass ionic-dissolution products on human fetal osteoblast-specific gene expression. Journal of Biomedical Materials Research Part B: Applied Biomaterials, 2005. 74B (1): p. 529-537.

[9] Tsigkou, O., et al., Differentiation of fetal osteoblasts and formation of mineralized bone nodules by $45 \mathrm{~S} 5$ Bioglass ${ }^{\circledR}$ conditioned medium in the absence of osteogenic supplements. Biomaterials, 2009. 30(21): p. 3542-3550.

[10] Gough, J. E., J. R. Jones, and L. L. Hench, Nodule formation and mineralisation of human primary osteoblasts cultured on a porous bioactive glass scaffold. Biomaterials, 2004. 25(11): p. 2039-2046.

[11] Eklou-Kalonji, E., et al., Effects of extracellular calcium on the proliferation and differentiation of porcine osteoblasts in vitro. Cell and Tissue Research, 1998. 292(1): p. 163-171.

[12] Catauro, M., et al., Biological influence of $\mathrm{Ca} / \mathrm{P}$ ratio on calcium phosphate coatings by sol-gel processing. Materials Science and Engineering: C, 2016. 65: p. 188-193.

[13] Galliano, P., et al., Sol-gel coatings on 316L steel for clinical applications. Journal of sol-gel science and technology, 1998. 13(1-3): p. 723-727.

[14] Hench, L. L., The story of Bioglass ${ }^{\circledR}$. Journal of Materials Science: Materials in Medicine, 2006. 17(11): p. 967-978.

[15] Stanislawski, L., et al., In vitro culture of human dental pulp cells: some aspects of cells emerging early from the explant. Clinical Oral Investigations, 1997. 1(3): p. 131-140.

[16] Freshney, R. I., Culture of animal cells. A Manual of Basic, 1994.

[17] Chou, L., et al., Effects of titanium on transcriptional and post-transcriptional regulation of fibronectin in human fibroblasts. Journal of Biomedical Materials Research, 1996. 31(2): p. 209-217.

[18] Wang, W. and T. Kirsch, Retinoic acid stimulates annexinmediated growth plate chondrocyte mineralization. The Journal of Cell Biology, 2002. 157(6): p. 1061-1070.

[19] Nakashima, M. and K. Iohara, Mobilized Dental Pulp Stem Cells for Pulp Regeneration: Initiation of Clinical Trial. Journal of Endodontics, 2014. 40(4, Supplement): p. S26-S32.

[20] Barthel, C. R., et al., TNF- $\alpha$ release in monocytes after exposure to calcium hydroxide treated Escherichia coli LPS. International Endodontic Journal, 1997. 30(3): p. 155-159.

[21] Modena, K. C. d. S., et al., cytotoxicity and biocompatibility of direct and indirect pulp capping materials. Journal of Applied Oral Science, 2009. 17(6): p. 544-554.

[22] Fava, L. R. G. and W. P. Saunders, Calcium hydroxide pastes: classification and clinical indications. International Endodontic Journal, 1999. 32(4): p. 257-282. 
[23] Accorinte, M. L. R., et al., Response of human pulps capped with different self-etch adhesive systems. Clinical Oral Investigations, 2008. 12(2): p. 119-127.

[24] Hebling, J., E. M. A. Giro, and C. A. de Souza Costa, Biocompatibility of an adhesive system applied to exposed human dental pulp. Journal of Endodontics, 1999. 25(10): p. 676-682.

[25] Schuurs, A. H. B., R. J. M. Gruythuysen, and P. R. Wesselink, Pulp capping with adhesive resin-based composite vs. calcium hydroxide: a review. Dental Traumatology, 2000. 16(6): p. 240-250.

[26] Dominguez, M. S., et al., Histological and Scanning Electron Microscopy Assessment of Various Vital Pulp-Therapy Materials. Journal of Endodontics, 2003. 29(5): p. 324-333.

[27] Asgary, S., et al., A comparative study of histologic response to different pulp capping materials and a novel endodontic cement. Oral Surgery, Oral Medicine, Oral Pathology, Oral Radiology, and Endodontology, 2008. 106(4): p. 609-614.

[28] Hørsted, P., K. El Attar, and K. Langeland, Capping of monkey pulps with Dycal and a Ca-eugenol cement. Oral Surgery, Oral Medicine, Oral Pathology, 1981. 52(5): p. 531553.

[29] Estrela, C. and R. Holland, Calcium hydroxide: study based on scientific evidences. Journal of Applied Oral Science, 2003. 11: p. 269-282.

[30] Torabinejad, M., T. F. Watson, and T. R. Pitt Ford, Sealing ability of a mineral trioxide aggregate when used as a root end filling material. Journal of Endodontics, 1993. 19(12): p. 591595.

[31] McNamara, R. P., et al., Biocompatibility of Accelerated Mineral Trioxide Aggregate in a Rat Model. Journal of Endodontics, 2010. 36(11): p. 1851-1855.

[32] Zhu, C., B. Ju, and R. Ni, Clinical outcome of direct pulp capping with MTA or calcium hydroxide: a systematic review and meta-analysis. International Journal of Clinical and Experimental Medicine, 2015. 8(10): p. 17055-17060.

[33] Roberts, H. W., et al., Mineral trioxide aggregate material use in endodontic treatment: A review of the literature. Dental Materials, 2008. 24(2): p. 149-164.

[34] Parirokh, M. and M. Torabinejad, Mineral Trioxide Aggregate: A Comprehensive Literature Review-Part I: Chemical, Physical, and Antibacterial Properties. Journal of Endodontics, 2010. 36(1): p. 16-27.

[35] Zhai, W., et al., Silicate bioceramics induce angiogenesis during bone regeneration. Acta Biomaterialia, 2012. 8(1): p. 341-349.

[36] Huang, Y., et al., In vitro and in vivo evaluation of akermanite bioceramics for bone regeneration. Biomaterials, 2009. 30(28): p. 5041-5048.

[37] Chou, L., et al. Atomic and Molecular Mechanisms Underlying the Osteogenic Effects of Bioglass [R] Materials. in bioceramics-conference-. 1998.

[38] Keeting, P. E., et al., Zeolite a increases proliferation, differentiation, and transforming growth factor $\beta$ production in normal adult human osteoblast-like cells in vitro. Journal of Bone and Mineral Research, 1992. 7(11): p. 1281-1289.
[39] Matsuoka, H., et al., In vitro analysis of the stimulation of bone formation by highly bioactive apatite- and wollastonitecontaining glass-ceramic: Released calcium ions promote osteogenic differentiation in osteoblastic ROS17/2.8 cells. Journal of Biomedical Materials Research, 1999. 47(2): p. 176-188.

[40] Dvorak, M. M., et al., Physiological changes in extracellular calcium concentration directly control osteoblast function in the absence of calciotropic hormones. Proceedings of the National Academy of Sciences of the United States of America, 2004. 101(14): p. 5140-5145.

[41] Knabe, C., et al., Morphological evaluation of osteoblasts cultured on different calcium phosphate ceramics. Biomaterials, 1997. 18(20): p. 1339-1347.

[42] Vrouwenvelder, W. C. A., C. G. Groot, and K. de Groot, Behaviour of fetal rat osteoblasts cultured in vitro on bioactive glass and nonreactive glasses. Biomaterials, 1992. 13(6): p. 382-392.

[43] Li, P., et al., The role of hydrated silica, titania, and alumina in inducing apatite on implants. Journal of Biomedical Materials Research, 1994. 28(1): p. 7-15.

[44] Sautier, J. M., et al., Bioactive glass-ceramic containing crystalline apatite and wollastonite initiates biomineralization in bone cell cultures. Calcified Tissue International, 1994. 55(6): p. 458-466.

[45] Loty, C., et al., Bioactive Glass Stimulates In Vitro Osteoblast Differentiation and Creates a Favorable Template for Bone Tissue Formation. Journal of Bone and Mineral Research, 2001. 16(2): p. 231-239.

[46] Yang, X., et al., The odontogenic potential of STRO-1 sorted rat dental pulp stem cells in vitro. Journal of Tissue Engineering and Regenerative Medicine, 2007. 1(1): p. 66-73.

[47] Väkevä, L., et al., Comparison of the distribution patterns of tenascin and alkaline phosphatase in developing teeth, cartilage, and bone of rats and mice. The Anatomical Record, 1990. 228(1): p. 69-76.

[48] Butler, W. T., et al., Isolation, Characterization and Immunolocalization of a 53-kDal Dentin Sialoprotein (DSP). Matrix, 1992. 12(5): p. 343-351.

[49] Couble, M.-L., et al., Odontoblast Differentiation of Human Dental Pulp Cells in Explant Cultures. Calcified Tissue International, 2000. 66(2): p. 129-138.

[50] Kim, J., et al., Evaluation of reparative dentin formation of ProRoot MTA, Biodentine and Bio Aggregate using micro-CT and immunohistochemistry. Restorative Dentistry \& Endodontics, 2016. 41(1): p. 29-36.

[51] Chaudhary, S. C., et al., Phosphate induces formation of matrix vesicles during odontoblast-initiated mineralization in vitro. Matrix Biology, 2016. 52-54: p. 284-300.

[52] Montazerolghaem, M., H. Engqvist, and M. Karlsson Ott, Sustained release of simvastatin from premixed injectable calcium phosphate cement. Journal of Biomedical Materials Research Part A, 2014. 102(2): p. 340-347.

[53] Lian, J. B. and G. S. Stein, Concepts of osteoblast growth and differentiation: basis for modulation of bone cell development and tissue formation. Critical Reviews in Oral Biology \& Medicine, 1992. 3(3): p. 269-305. 